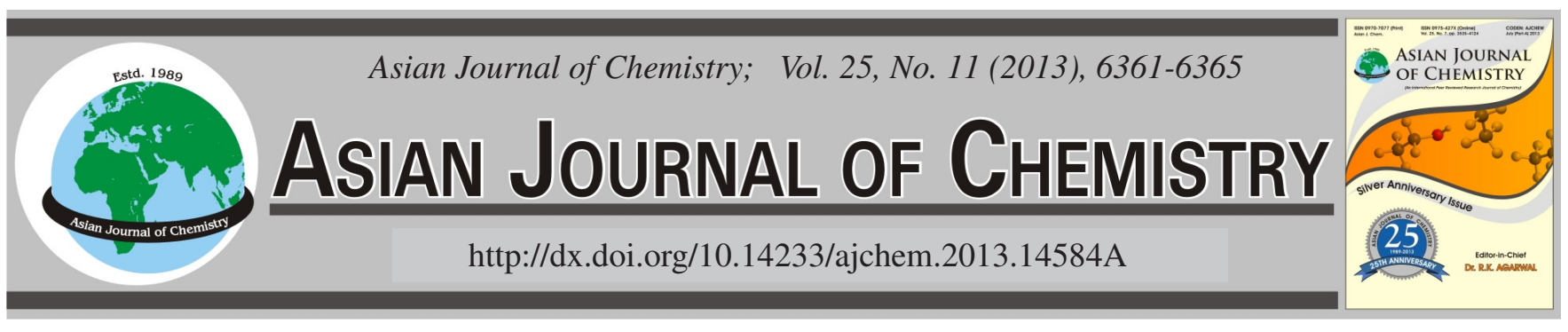

\title{
Phytochemical Compositions of the Essential Oil from Blumea balsamifera
}

\author{
Yu-XIAN LI ${ }^{1, *}$, XIAO-Hong PeI ${ }^{2}$, Dong-QIng JiAnG ${ }^{3}$ and Ke YuAN ${ }^{3}$
}

${ }^{1}$ College of Pharmacy, Henan University of Traditional Chinese Medicine, Zhengzhou 450008, P.R. China

${ }^{2}$ Pingdingshan City Environmental Monitoring Center Station, Pingdingshan 467000, P.R. China

${ }^{3}$ Zhejiang Agriculture and Forestry University, Lin'an 311300, P.R. China

*Corresponding author: Tel: +86 371 65962746; E-mail: liyuxian0011@163.com

(Received: 17 September 2012;

Accepted: 10 May 2013)

AJC-13472

\begin{abstract}
To analyze the chemical constituents of the volatile oil in the green peel of Blumea balsamifera. The chemical constituents was extracted from the Blumea balsamifera by HS-SPME. The components of phytochemical constituents of the volatile oil separated and identified by GC-MS. The relative content of each component was determined by area normalization. Seventy-one kinds of components were separated. Among them, 67 components were identified, accounting about $98.56 \%$ of the total chemical constituents, most of that belong to sesquiterpenoids, the main chemical constituents of the Blumea balsamifera are compounds 1: caryophyllene (26.47 \%); compound 2: thujopsene-I3 (14.45\%); compound 3: 1,7,7-trimethyl-(1S-endo)-bicyclo[2.2.1]heptan-2-ol (9.07\%); compound 4: 3-t-butyl-4methoxyphenol methyl derivative (6.91\%); compound 5: 1R, 4R, 7R, 11R-1, 3, 4, 7-tetramethyltricyclo[5.3.1.0(4,11)]undec-2-ene (6.03); compound 6: caryophyllene oxide (5.38 \%); compound 7: 1-methyl-3-(1-methylethyl)-benzene (2.89\%); compound 8: 1,1,4,8tetramethyl-cis, cis, cis- 4,7,10- cycloundecatriene (2.36 \%) etc. This experimental result enhances the understanding of phytochemical constituents of volatile oils in Blumea balsamifera and provides further reference for the development and utilization of the natural medicinal resource.
\end{abstract}

Key Words: Blumea balsamifera, Volatile oil, HS-SPME, GC-MS.

\section{INTRODUCTION}

Blumea balsamifera belongs to the aromatic plants of asteraceae family named Blumea balsamifera (Linn.) DC. Its medicinal parts are branches and leaves, twigs and twig stems. These medicinal parts can be picked the whole year, with its best quality when picked in fall. Dry them in the sun after picking them up ${ }^{1,2}$. Its other names are Dafeng (big wind) herb, Bingpian(ice flake) herb, Jiafeng (family wind) herb, Damao (big hair) medicine, Da'ai (big herb), etc. It is mainly distributed in the areas of Fujian, Taiwan, Guizhou, Hainan Island, Yunnan, etc. Blumea balsamifera has the medical effects of worm-killing, expelling wind, removing dampness, warming middle and stopping diarrhea, activating blood and detoxication, dredging all the body apertures and dispersing stagnated fire in the body, swelling-reducing and pain-alleviating. It is mainly used to cure anemofrigid cold, stroke and headache, rheumatism and spleen pain, cold-dampness and diarrhea, pinworm illness, viper biting, physique pain, traumatic pains and ringworms, etc. ${ }^{3,4}$. The pharmacological study shows that the injection of the Blumea balsamifera extracts into the animals can have the following medical effects i.e., lowering blood-pressure, expanding the blood vessels, suppressing the sympathetic nervous system, which can be used for the patients of overexciting, insomnia, or hypertension. It is also reported that Blumea balsamifera has the functions of diuresis, warming middle and invigorating blood circulation, expelling wind and removing dampness and worm-killing, etc. ${ }^{5,6}$.

Solid-phase microextraction (SPME) $)^{7-10}$ came into research in the $1990 \mathrm{~s}$ and developed very fast ever since. It is a newstyle, eco-friendly sample pre-treatment technology without using the organic solutions, which is very easy to operate. It has the advantages of fast analytical speed (generally can reach the adsorption balance in 2 30 min), high sensibility, good repeatability, etc. It integrates collection, extraction, gathering and sample-feeding into one. This technology uses portable extractor, suitable to be used for the instant sample-taking and analysis both indoors and outdoors and it is also suitable for automatic operation. This is very important for the common analysis for the large amount of samples with short operating cycle. It has great significance both in labour-and-time saving and in improving the precision and repeatability of this method.

Through literature retrieval, we find that up to now, there has been no report on the research of the solid-phase microextraction, SPME for the volatile oil in the aromatic plant Blumea balsamifera and its component analysis. Blumea 
balsamifera belongs to the aromatic plant which has a relatively high content of the volatile oil. It is abundant in its wild resources. This thesis takes the method of headspace solid-phase microextraction (HS-SPME) to extract the volatile oil component in Blumea balsamifera, uses gas chromatograph-mass spectrometer to determine the chemical components in its volatile oil and takes the peak area normalization method to measure the relative percentage of the volatile oil components and thus separates 71 component groups and determines 67 kinds of compounds. The determined components take up about $98.56 \%$ of the total peak area. We also calculate the relative contents in each peak by the method of peak area normalization. This provides the reference data for the further research of its active components in the volatile oil of the Blumea balsamifera.

\section{EXPERIMENTAL}

Trace MS GC-MC (gas chromatograph-mass spectrometer) (American Finigen Company); chromatographic column is DB-WAX (30 $\mathrm{m} \times 0.25 \mathrm{~mm}, 0.25 \mathrm{~mm})$, a elastic quartz capillary column; manual solid-phase micro-extraction, SPME (American Supelco company), the extraction fiber head is: $65 \mu \mathrm{m}$ PDMS/DVB. $\mathrm{C}_{8}-\mathrm{C}_{20}$ and $\mathrm{C}_{21}-\mathrm{C}_{40}$ mixed hydrocarbon alkyl guide sample.

Blumea balsamifera (Linn.) DC was picked up in Sanya city, Hainan Island in August, 2011 and was determined by Professor Huang Shiman, majored in the taxology of the medicinal plant, Hainan University.

SPME conditions: Weigh $1 \mathrm{~g}$ of the leaf powder of Blumea balsamifera and put it in the $15 \mathrm{~mL}$ sample flask of exclusive use and insert it into the manual sample-feeding machine with the fiber head of $65 \mu \mathrm{m}$ PDMS/DVB, then take it out after extracting for $0.5 \mathrm{~h}$ by the method of headspace solid-phase micro-extraction under $90{ }^{\circ} \mathrm{C}$ with the magnetic stirring speed of $1100 \mathrm{rpm}$ and finally insert at once into the chromatograph sample-feeding mouth (temperature $250{ }^{\circ} \mathrm{C}$ ) with the desorption time of $2.5 \mathrm{~min}$.

Analytical conditions of the gas chromatograph-mass spectrometer: The gas chromatograph conditions: the chromatographic column is DB-WAX $(30 \mathrm{~m} \times 0.25 \mathrm{~mm}, 0.25 \mathrm{~mm})$ quartz capillary column; The temperature rising procedure: the initial temperature is kept at $45^{\circ} \mathrm{C}$ for $3 \mathrm{~min}$, then raise the temperature to $100^{\circ} \mathrm{C}$ for $15 \mathrm{~min}$ at the speed of $10^{\circ} \mathrm{C} \mathrm{min}^{-1}$, then again raise to $170{ }^{\circ} \mathrm{C}$ at the speed of $5^{\circ} \mathrm{C} \mathrm{min}{ }^{-1}$; to $240{ }^{\circ} \mathrm{C}$ for $7 \mathrm{~min}$ at the speed of $10^{\circ} \mathrm{C} \mathrm{min}^{-1}$; the temperature at the sample-feeding mouth is $250{ }^{\circ} \mathrm{C}$ and the temperature at the vaporizing room is $250^{\circ} \mathrm{C}$; the carrier gas is helium (He) flowing speed is $0.8 \mathrm{~mL} \mathrm{~min}^{-1}$, no bypass flow, with the sample-feeding amount $1.0 \mathrm{~mL}$ and the flowing ration 50:1.

Mass spectrum conditions: Electronic bombardment ion source (EI); the ionizing energy is $70 \mathrm{eV}$, the temperature of the ion source is $200{ }^{\circ} \mathrm{C}$, the voltage of the detector is $350 \mathrm{~V}$, the detecting range is between $40-300 \mathrm{~m} \cdot \mathrm{z}^{-1}$, the interval of the detection is $0.5 \mathrm{~s}$; the scanning mass range is $m / z: 333 \sim 500$ AMU; the scanning speed is $0.5 \mathrm{~s}$; the retrieved atlas databanks are Willey and NIST standard mass spectrum data-bank.

Calculation of retention indices: This quasi-linear equation proposed by Van den Dool and Kratz was used to calculate retention indices in this work:

$$
\mathrm{IT}=100 * \mathrm{n}+100 *(\mathrm{tx}-\mathrm{tn}) /(\mathrm{tn}+1-\mathrm{tn})
$$

where IT is the temperature-programmed retention index of the interesting compound and $\mathrm{tn}, \mathrm{tn}+1$ and $\mathrm{tx}$ are the retention times of the two standard $n$-alkanes containing $n$ and $n+1$ carbons and the compound of interest, respectively.

Determination results: This research adopts the DBWAX capillary column, takes a suitable amount of samples and determines and analyze by the gas chromatograph-mass spectrometer and thus obtains the total ion flow chart of the volatile oil in Blumea balsamifera (Fig. 1). We get the mass spectrum map after scanning for each chromatographic peak and retrieving and consulting the related mass-spectrum literature by NIST 2008 standard. The quantification of the compounds takes the area normalization method and using Hewlett-Packard soft-ware treatment system to calculate each peak area and thus obtains the relative percentage of the volatile oil in each component. And calculate its RI value by choosing the probable matter with the relative higher mass-spectrum matching degree and combine the manual analysis to determine chemical components in the volatile oil in Blumea balsamifera (Table-1).

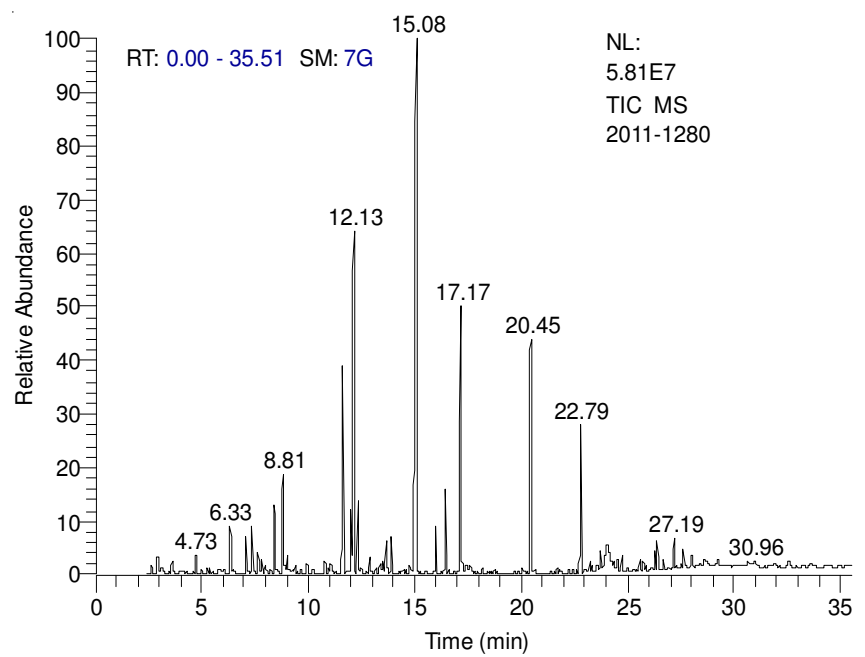

Fig. 1. GC-MS total ion current chromatogram of the volatile oil in the Blumea balsamifera

As can be seen from Table-1, we determined overall 67 kinds of compounds from the volatile oil in Blumea balsamifera. The determined components take up $98.56 \%$ of the total peak area and the highest compound contents in the volatile oil of Blumea balsamifera are all sesquiterpene besides the small molecular aromatic components. It has already known that the above sesquiterpene components have very strong bacteriostasis and certain anti-oxidation activity as well as some cyto-toxicity ${ }^{11-13}$. The main components in the volatile oil of Blumea balsamifera are mainly: compounds 1: caryophyllene (26.47\%); compound 2: Thujopsene-I3 (14.45\%); Compound 3: 1,7,7-trimethyl-(1S-endo) -bicyclo[2.2.1]heptan2-ol (9.07\%); compound 4: 3-t-butyl-4-methoxyphenol methyl derivative (6.91\%); compound 5: 1R, 4R, 7R, 11R-1, 3,4,7tetramethyltricyclo[5.3.1.0(4,11)] undec-2-ene (6.03); compound 6: caryophyllene oxide $(5.38 \%)$; compound 7: 1methyl-3-(1-methylethyl)-benzene (2.89\%); compound 8: 1,1,4,8-tetramethyl-cis,cis,cis-4,7,10- cycloundecatriene 
TABLE-1

ANALYTICAL RESULTS OF CHEMICAL CONSTITUENTS OF THE VOLATILE OIL IN THE BLUMEA BALSAMIFERA

\begin{tabular}{|c|c|c|c|c|c|}
\hline No. & Name of components & $\begin{array}{l}\mathrm{RT} \\
(\mathrm{min})\end{array}$ & m.f. & RI & $\begin{array}{c}\text { Relative } \\
\text { concent }(\%)\end{array}$ \\
\hline 1 & 2-Methyl-furan & 2.63 & $\mathrm{C}_{5} \mathrm{H}_{6} \mathrm{O}$ & 869.737 & 0.42 \\
\hline 2 & 2-Butanone & 2.94 & $\mathrm{C}_{4} \mathrm{H}_{8} \mathrm{O}$ & 905.674 & 0.72 \\
\hline 3 & 2-Methyl-butanal & 3.10 & $\mathrm{C}_{5} \mathrm{H}_{10} \mathrm{O}$ & 917.021 & 0.53 \\
\hline 4 & 2-Ethyl-furan & 3.62 & $\mathrm{C}_{6} \mathrm{H}_{10} \mathrm{O}$ & 953.901 & 0.45 \\
\hline 5 & 4-Methyl-1-(1-methylethyl)-didehydro derive bicycle [3.1.0] hexane & 4.73 & $\mathrm{C}_{10} \mathrm{H}_{16}$ & 1026.590 & 0.44 \\
\hline 6 & 1-(2-Methyl-1-cyclopenten-1-yl)-ethanone & 5.24 & $\mathrm{C}_{8} \mathrm{H}_{14} \mathrm{O}$ & 1056.069 & 0.11 \\
\hline 7 & Camphene & 5.35 & $\mathrm{C}_{10} \mathrm{H}_{16}$ & 1062.428 & 0.12 \\
\hline 8 & $\alpha$-Phellandrene & 6.33 & $\mathrm{C}_{10} \mathrm{H}_{16}$ & 1119.298 & 1.28 \\
\hline 9 & $\alpha$-Pinene & 7.07 & $\mathrm{C}_{10} \mathrm{H}_{16}$ & 1162.573 & 1.07 \\
\hline 10 & $(+)$-2-Caren & 7.34 & $\mathrm{C}_{10} \mathrm{H}_{20}$ & 1178.363 & 1.13 \\
\hline 11 & D-Limonene & 7.65 & $\mathrm{C}_{10} \mathrm{H}_{16}$ & 1196.491 & 0.57 \\
\hline 12 & 4-Methyl-1-(1-methylethyl)-bicyclo[3.1.0]hex-2-ene & 7.81 & $\mathrm{C}_{10} \mathrm{H}_{16}$ & 1206.98 & 0.38 \\
\hline 13 & 2-Hexen & 7.97 & $\mathrm{C}_{6} \mathrm{H}_{10} \mathrm{O}$ & 1215.854 & 0.18 \\
\hline 14 & 1,6-Dimethylhepta-1,3,5-triene & 8.03 & $\mathrm{C}_{9} \mathrm{H}_{14}$ & 1219.512 & 0.11 \\
\hline 15 & 2-Pentyl-furan & 8.18 & $\mathrm{C}_{8} \mathrm{H}_{14} \mathrm{O}$ & 1228.144 & 0.08 \\
\hline 16 & 1-Methyl-4-(1-methylethyl)-1,4-cyclohexadiene & 8.42 & $\mathrm{C}_{10} \mathrm{H}_{16}$ & 1243.293 & 1.43 \\
\hline 17 & (Z)-2-Nonen-1-ol & 8.55 & $\mathrm{C}_{9} \mathrm{H}_{18} \mathrm{O}$ & 1251.220 & 0.11 \\
\hline 18 & 1-Methyl-3-(1-methylethyl)-benzene & 8.81 & $\mathrm{C}_{10} \mathrm{H}_{14}$ & 1267.073 & 2.89 \\
\hline 19 & 1-Methyl-4-(1-methylethylidene)-cyclohexene & 9.02 & $\mathrm{C}_{10} \mathrm{H}_{16}$ & 1279.878 & 0.58 \\
\hline 20 & 2-Ethenyl-1,1-dimethyl-3-methylene-cyclohexane & 9.40 & $\mathrm{C}_{11} \mathrm{H}_{18}$ & 1302.793 & 0.18 \\
\hline 21 & 6-Methyl-5-hepten-2-one & 9.93 & $\mathrm{C}_{8} \mathrm{H}_{14} \mathrm{O}$ & 1332.402 & 0.21 \\
\hline 22 & 1-Hexanol & 10.23 & $\mathrm{C}_{6} \mathrm{H}_{14} \mathrm{O}$ & 1349.162 & 0.15 \\
\hline 23 & (Z)-3-Hexen-1-ol & 10.79 & $\mathrm{C}_{6} \mathrm{H}_{12} \mathrm{O}$ & 1380.447 & 0.28 \\
\hline 24 & 3-Octanol & 10.94 & $\mathrm{C}_{8} \mathrm{H}_{18} \mathrm{O}$ & 1388.827 & 0.17 \\
\hline 25 & Tetradecane & 11.07 & $\mathrm{C}_{14} \mathrm{H}_{30}$ & 1396.089 & 0.29 \\
\hline 26 & 1R, 4R, 7R, 11R-1, 3, 4, 7-tetramethyltricyclo[5.3.1.0(4,11)]undec-2-ene & 11.62 & $\mathrm{C}_{15} \mathrm{H}_{24}$ & 1424.742 & 6.03 \\
\hline 27 & 1-Octen-3-ol & 11.99 & $\mathrm{C}_{8} \mathrm{H}_{16} \mathrm{O}$ & 1443.814 & 1.77 \\
\hline 28 & Thujopsene-I3 & 12.13 & $\mathrm{C}_{14} \mathrm{H}_{22}$ & 1451.031 & 14.45 \\
\hline 29 & Longifolene-(V4) & 12.48 & $\mathrm{C}_{15} \mathrm{H}_{24}$ & 1469.072 & 0.14 \\
\hline 30 & $\alpha$-Cubebene & 12.86 & $\mathrm{C}_{15} \mathrm{H}_{24}$ & 1488.660 & 0.20 \\
\hline 31 & 1,5,9,9-Tetramethyl-(isocaryophyllene-I1)(-)-tricyclo [6.2.1.0 (4,11)]undec-5-ene & 13.21 & $\mathrm{C}_{15} \mathrm{H}_{26}$ & 1506.404 & 0.15 \\
\hline 32 & 1,7,7-Trimethyl-(1S)-bicyclo[2.2.1]heptan-2-one & 13.35 & $\mathrm{C}_{10} \mathrm{H}_{16} \mathrm{O}$ & 1513.300 & 0.13 \\
\hline 33 & Benzaldehyde & 13.41 & $\mathrm{C}_{7} \mathrm{H}_{6} \mathrm{O}$ & 1516.256 & 0.27 \\
\hline 34 & Aromadendrene, dehydro- & 13.52 & $\mathrm{C}_{15} \mathrm{H}_{22}$ & 1521.675 & 0.36 \\
\hline 35 & Guaia-3,9-diene & 13.62 & $\mathrm{C}_{15} \mathrm{H}_{24}$ & 1526.601 & 0.20 \\
\hline 36 & $\begin{array}{l}\text { 2,3,6,7,8,8 } \alpha \text {-hexahydro-1,4,9,9-tetramethyl-( } 1 \alpha, 3 \alpha \alpha, 7 \alpha, 8 \alpha \alpha)-1 \mathrm{H}-3 \alpha, 7- \\
\text { methanoazulene }\end{array}$ & 13.67 & $\mathrm{C}_{15} \mathrm{H}_{24}$ & 1529.064 & 1.04 \\
\hline 37 & 3,7-Dimethyl-1,6-octadien-3-ol & 13.88 & $\mathrm{C}_{10} \mathrm{H}_{18} \mathrm{O}$ & 1539.409 & 0.86 \\
\hline 38 & 6-Isopropylidene-bicyclo[3.1.0]hexane & 13.94 & $\mathrm{C}_{9} \mathrm{H}_{14}$ & 1542.365 & 0.26 \\
\hline 39 & 2,2-Dimethyl-1-(2,4,6-trimethylphenyl)propan-1-one & 14.75 & $\mathrm{C}_{14} \mathrm{H}_{20} \mathrm{O}$ & 1582.266 & 0.27 \\
\hline 40 & 1-Ethenyl-1-methyl-2,4-bis(1-methylethenyl)-[1S-(1 $\alpha, 2 \alpha, 4 \alpha)]$-cyclohexane & 14.83 & $\mathrm{C}_{15} \mathrm{H}_{24}$ & 1586.207 & 0.17 \\
\hline 41 & Caryophyllene & 15.08 & $\mathrm{C}_{15} \mathrm{H}_{24}$ & 1598.522 & 26.47 \\
\hline 42 & $\begin{array}{l}\text { Decahydro-1,1,7-trimethyl-4-methylene-[1 } 1 \alpha \mathrm{R}-(1 \alpha \alpha, 4 \alpha \alpha, 7 \alpha, 7 \alpha \alpha, 7 \alpha \beta)]-1 \mathrm{H}- \\
\text { cycloprop[e]azulene }\end{array}$ & 15.96 & $\mathrm{C}_{15} \mathrm{H}_{24}$ & 1640.670 & 1.23 \\
\hline 43 & 1,1,4,8-Tetramethyl-cis,cis,cis-4,7,10- cycloundecatriene & 16.45 & $\mathrm{C}_{15} \mathrm{H}_{24}$ & 1664.115 & 2.36 \\
\hline 44 & 1,7,7-Trimethyl-(1S-endo)-bicyclo[2.2.1]heptan-2-ol & 17.17 & $\mathrm{C}_{10} \mathrm{H}_{18} \mathrm{O}$ & 1698.565 & 9.07 \\
\hline 45 & $\begin{array}{l}1,2,3,5,6,7,8,8 \alpha \text {-octahydro-1,8 } \alpha \text {-dimethyl-7-(1-methylethenyl)-[1S-(1 } \alpha, 7 \alpha, 8 \alpha \alpha)] \text { - } \\
\text { naphthalene }\end{array}$ & 17.42 & $\mathrm{C}_{15} \mathrm{H}_{24}$ & 1710.577 & 0.20 \\
\hline 46 & Eudesma-4(14),11-diene & 17.46 & $\mathrm{C}_{15} \mathrm{H}_{24}$ & 1712.500 & 0.10 \\
\hline 47 & 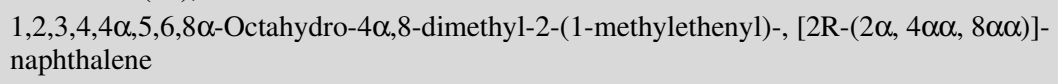 & 17.54 & $\mathrm{C}_{15} \mathrm{H}_{24}$ & 1716.346 & 0.23 \\
\hline 48 & 3-Methyl-4-propyl-2,5-furandione & 17.61 & $\mathrm{C}_{8} \mathrm{H}_{12} \mathrm{O}_{3}$ & 1719.712 & 0.16 \\
\hline 49 & $\begin{array}{l}1,2,4 \alpha, 5,8,8 \alpha \text {-Hexahydro-4,7-dimethyl-1-(1-methylethyl)-[1S-(1 } \alpha, 4 \alpha \alpha, 8 \alpha \alpha)]- \\
\text { naphthalene }\end{array}$ & 18.19 & $\mathrm{C}_{15} \mathrm{H}_{24}$ & 1747.596 & 0.13 \\
\hline 50 & Hexanoic acid & 20.04 & $\mathrm{C}_{6} \mathrm{H}_{12} \mathrm{O}_{2}$ & 1837.255 & 0.21 \\
\hline 51 & 3-t-Butyl-4-methoxyphenol methyl derivative & 20.45 & $\mathrm{C}_{12} \mathrm{H}_{18} \mathrm{O}$ & 1857.353 & 6.91 \\
\hline 52 & Decahydro-1,1,4,7-tetramethyl-[1 $\alpha$-(14Ah-cycloprop[e]azulen- $4 \alpha$-ol & 21.68 & $\mathrm{C}_{15}{ }^{22} \mathrm{H}_{26} \mathrm{O}$ & 1917.647 & 0.12 \\
\hline 53 & Caryophyllene oxide & 22.79 & $\mathrm{C}_{15} \mathrm{H}_{24} \mathrm{O}$ & 1972.059 & 5.38 \\
\hline 54 & 1,2-dimethoxy-4-(2-propenyl)-benzene & 23.24 & $\mathrm{C}_{11} \mathrm{H}_{14} \mathrm{O}$ & 1994.118 & 0.26 \\
\hline 55 & $\begin{array}{l}\text { Decahydro-1,1,4,7-tetramethyl-[1 } \alpha-(1 \alpha \alpha, 4 \alpha, 4 \alpha \alpha, 7 \alpha, 7 \alpha \alpha, 7 \alpha \beta)]-1 \mathrm{H}- \\
\text { cycloprop[e]azulen-4-ol }\end{array}$ & 23.58 & $\mathrm{C}_{15} \stackrel{2}{\mathrm{H}} \mathrm{2}_{26} \mathrm{O}$ & 2021.019 & 0.13 \\
\hline
\end{tabular}




\begin{tabular}{|c|c|c|c|c|c|}
\hline No. & Name of components & $\begin{array}{c}\mathrm{RT} \\
(\mathrm{min})\end{array}$ & m.f. & RI & $\begin{array}{l}\text { Relative } \\
\text { concent }(\%)\end{array}$ \\
\hline 56 & 1,5,5,8-tetramethyl-[1R-(1R*,3E,7E,11R*)]-12-oxabicyclo[9.1.0]dodeca-3,7-diene & 23.72 & $\mathrm{C}_{15} \mathrm{H}_{24}$ & 2029.936 & 0.65 \\
\hline 57 & Cubenol & 24.03 & $\mathrm{C}_{15} \mathrm{H}_{26} \mathrm{O}$ & 2049.682 & 0.25 \\
\hline 58 & 4-Ethenyl- $\alpha, \alpha, 4$-trimethyl-3-(1-methylethenyl)-[1R-(1 $\alpha, 3 \alpha, 4 \alpha)]$-cyclohexanemethanol & 24.36 & $\mathrm{C}_{15} \mathrm{H}_{26} \mathrm{O}$ & 2070.701 & 0.16 \\
\hline 59 & $1,2,3,4,5,6,7,8$-Octahydro- $\alpha, \alpha, 3,8$-tetramethyl-5-azulenemethanol & 24.52 & $\mathrm{C}_{15} \mathrm{H}_{26} \mathrm{O}$ & 2080.892 & 0.24 \\
\hline 60 & $\begin{array}{l}1 \alpha, 2,3,4,4 \alpha, 5,6,7 b-\text { octahydro-1,1,4,7-tetramethyl-[1 }[\alpha \mathrm{R}-(1 \alpha \alpha, 4 \alpha, 4 \alpha \alpha, 7 \alpha \beta)]-1 \mathrm{H}- \\
\text { cycloprop[e]azulene }\end{array}$ & 24.74 & $\mathrm{C}_{15} \mathrm{H}_{24} \mathrm{O}$ & 2094.904 & 0.41 \\
\hline 61 & Guaiol & 25.62 & $\mathrm{C}_{15} \mathrm{H}_{26} \mathrm{O}$ & 2175.471 & 0.45 \\
\hline 62 & $1,2,3,4,4 \alpha, 5,6,8 \alpha$-octahydro- $\alpha, \alpha, 4 \alpha, 8$-tetramethyl- $(2 \alpha, 4 \alpha \alpha, 8 \alpha \alpha)$-2-naphthalenemethanol & 26.29 & $\mathrm{C}_{15} \mathrm{H}_{26} \mathrm{O}$ & 2213.158 & 0.39 \\
\hline 63 & Decahydro- $\alpha, \alpha, 4 \alpha$-trimethyl-8-methylene-,2-naphthalenemethanol & 26.40 & $\mathrm{C}_{15} \mathrm{H}_{28} \mathrm{O}$ & 2222.807 & 0.77 \\
\hline 64 & 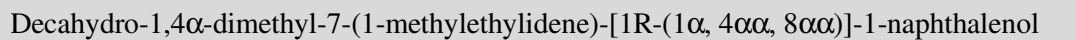 & 26.68 & $\mathrm{C}_{15} \mathrm{H}_{26} \mathrm{O}$ & 2247.368 & 0.24 \\
\hline 65 & 4,4-Dimethyl-tetracyclo[6.3.2.0(2,5).0(1,8)]tridecan-9-ol & 27.19 & $\mathrm{C}_{15} \mathrm{H}_{24} \mathrm{O}$ & 2292.105 & 0.83 \\
\hline 66 & $(3 \alpha, 5 \alpha)$-Androstan-3-ol & 28.60 & $\mathrm{C}_{19} \mathrm{H}_{34} \mathrm{O}$ & & 0.51 \\
\hline 67 & 2,6,10,14,18-Pentamethyl-2,6,10,14,18-eicosapentaene & 30.96 & $\mathrm{C}_{25} \mathrm{H}_{42}$ & & 0.52 \\
\hline
\end{tabular}

(2.36\%); Compound 9: 1-methyl-4-(1-methylethyl)-1,4cyclohexadiene $(1.43 \%)$; compound 10: $\alpha$-phellandrene $(1.28 \%)$; compound 11: (+)-2-caren (1.13\%); compound 12: $\alpha$-pinene (1.07\%) (Fig. 2).

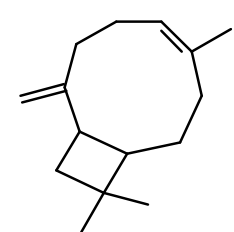

Compound 1

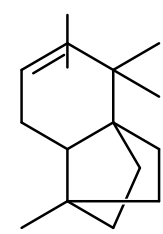

Compound 2

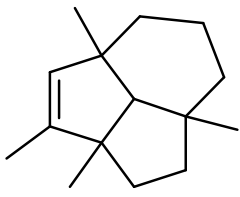

Compound $\mathbf{5}$

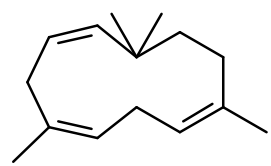

Compound $\mathbf{8}$

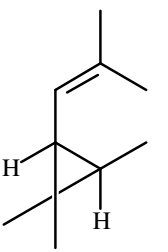

Compound 11

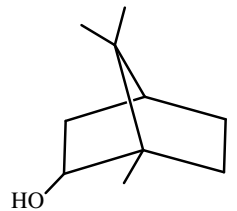

Compound 3

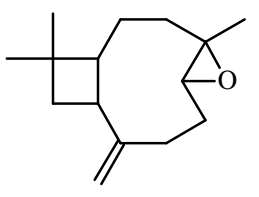

Compound 6
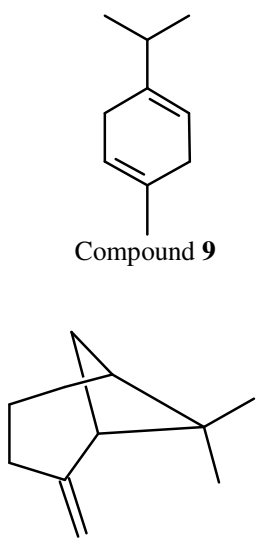

Compound 12
Compound $\mathbf{1 0}$

Fig. 2. Representative volatile compounds of essential oils from Blumea balsamifera

\section{RESULTS AND DISCUSSION}

We determined overall 67 kinds of compounds from the volatile oil in Blumea balsamifera. The determined components take up $98.56 \%$ of the total peak area and the highest compound contents in the volatile oil of Blumea balsamifera are all sesquiterpene besides the small molecular aromatic components. The main components in the volatile oil of
Blumea balsamifera are mainly Caryophyllene; ThujopseneI3; 1,7,7-trimethyl-(1S-endo)-bicyclo[2.2.1]heptan-2-ol; 3-tbutyl-4-methoxyphenol methyl derivative; 1R, 4R, 7R, 11R1,3,4,7-tetramethyltricyclo[5.3.1.0(4,11)]undec-2-ene; caryophyllene oxide;1-methyl-3-(1-methylethyl)-benzene; 1,1,4,8-tetramethyl-cis,cis,cis-4,7,10-cycloundecatriene, etc.

The method of solid phase microextraction has two steps of adsorption and desorption. In the process of adsorption, the material to be determined is distributed equally in the sample and the fixed phase liquid film spread among the outside of the quartz fiber extracting head and it follows the rule of similar liquid with similar solvency. This step is mainly the process of physical adsorption, which can quickly reach balance. If we use the liquid polymerization coating, when the single component system reaches balance, the amount of the matter to be determined has a linear relationship with the matter to be determined in the sample. The desorption process is quite different with the difference of the later separating methods of SPME. For the gas chromatograph, the heat-desorption is conducted after the extracting fiber is put into the sample-feeding mouth; but for the liquid chromatograph, the elution is done through solvents. Although the one-time extracting ability of SPME is greatly lower than the commonly-used liquid-liquid extracting method, its absolute sample-feeding amount is much greater than the liquid-liquid extracting method and it has a very high sensibility. All in all, the advantages of SPME method are to extract without using organic solvent and thus it reduces the extracting cost, avoids the secondary pollution. It also has a very short operating time, about $1 \mathrm{~h}$ from the sample-feeding to the result analysis. In addition, it uses fewer samples and operates easily and can reduce the volatile loss of the components to be determined and therefore, it is very suitable in extracting the volatile organic solvent, semi-volatile organic matter and the organic matter without volatility.

This report has a comprehensive analysis of the chemical components in the volatile oil of Blumea balsamifera by the method of SPME-GC/MS (the solid-phase micro-extraction; gas chromatograph and mass-spectrum) and thus provides a reference data for the further exploitation of this natural resource.

\section{ACKNOWLEDGEMENTS}

The authors are grateful to Prof. Liping Wang, Analysis and Testing Centre, Jiangnan University, for performing GCMS and HS-SPME. 


\section{REFERENCES}

1. Y. Yuan, Y.X. Pang, W.Q. Wang, Y.B. Zhang, J.B. Yu and M. Zhu, Chinese J. Trop. Agric., 31, 22 (2011).

2. Y. Yuan, Y.X. Pang, W.Q. Wang, Y.B. Zhang and J.B. Yu, J. Trop. Organisms, 2, 78 (2011)

3. H. Liang, P.X. Cao, J.Y. Qiu, X. Li, L. Chai and G.Y. Liang, Lishizhen Medicine Mater. Medica Res., 22, 308 (2011).

4. M. Chen, H.Z. Jin, L. Yan, X.J. Hu, J.J. Tan, J.H. Liu, S.K. Yan and W.D. Zhang, Nat. Prod. Res. Dev., 22, 991 (2010).

5. Y.L. Huang, Z.G. Zhao and Y.X. Wen, Guihaia, 26, 453 (2006).

6. P.D. Xie, T. Sang and X.Z. Gong, China J. Chinese Materia Medica, 25, 27 (2000).
7. S.X. Jiang and J.J. Feng, Chinese J. Chromatogr., 30, 3 (2012).

8. J.L. Hu, P. Zheng and L. Hua, J. Hubei Univ. Educ., 29, 2 (2012).

9. W.C. Xie, X.H. Yang, C.H. Zhang, H.W. Ji and L.F. Zhang, Chinese J. Anal. Chem., 39, 12 (2010).

10. Z. He, Z.M. Lu, H.Y. Xu, J.S. Shi and Z.H. Xu, J. Chinese Med. Mater., 34, 11 (2011)

11. Y. Tambe, H. Tsujiuchi, G. Honda, Y. Ikeshiro and S.Tanaka, Planta Med., 62, 469 (1996).

12. C. Ghelardini, N. Galeotti, D.C. Mannelli, G. Mazzanti and A. Bartolini, Farmaco, 56, 387 (2001).

13. K.R. Park, D. Nam, H.M. Yun, S.G. Lee, H.J. Jang, G. Sethi, S.K. Cho and K.S. Ahn, Cancer Lett., 312, 178 (2011). 